\title{
WEAR OF HUMAN ENAMEL OPPOSING DIFFERENT TYPES OF DIRECT RESTORATIVE RESIN COMPOSITE MATERIALS
}

\author{
Hossam El Mandouh* and Mohammad S. Nassif ${ }^{* *}$
}

\begin{abstract}
Aim: to evaluate the wear of human enamel and different types of composite resin restorative materials when they oppose each other

Materials and methods: six different types of restorative resin composites (Grandioso, Activa, Z250, Brilliant everglow, CAPO, Herculite XRV) were opposed by human enamel in a chewing simulator (Robota, Germany) the chewing simulator was adjusted to perform a sliding distance of $1 \mathrm{~mm}$ under a constant force of $50 \mathrm{~N}$ while composite is in contact with enamel. the loss of weight of enamel and opposing composite was considered as a value for the wear.
\end{abstract}

Results: The highest wear was that of Grandioso heavy flow $(5.8 \mathrm{mg})$ followed by brilliant everglow (4mg) and Herculite ultra enamel $(2.5 \mathrm{mg})$ respectively and there was statistically significant differences among them as well as other materials. and the least values were recorded for CAPO (1.22mg), Z250 (1.24) and Activa (1.27) that were not statistically significantly different. Regarding opposing enamel wear the highest wear value was that of enamel opposing Brilliant everglow $(7 \mathrm{mg})$ and Z250 (6.4mg) both values were not statistically different. The values of Heculite ultra enamel (4.6) and Grandioso heavy flow (4mg) had no significant differences between them but showed significant difference with the above groups. The enamel wear opposing Activa $(1 \mathrm{mg})$ and CAPO $(1.8 \mathrm{mg})$ showed no statistically significant differences between them while they were significantly less than other groups.

Conclusions: Different composite formulations recommended for use in stress bearing areas have different wear rates, opposing enamel wear is important to study as it is independent of composite wear.

* Lecturer, Operative Dentistry Department, Faculty of Dentistry, Suize Canal University.

** Assistant Professor, Biomaterials Department, Faculty of Dentistry, Ain Shams University. 


\section{INTRODUCTION}

Wear of restorative composites is a major concern only in occlusal stress bearing areas and especially for patients with parafunctional habits as bruxism. ${ }^{(1-3)}$ Randomized clinical trials revealed that there is no significant differences in wear between nonofilled composites and microhybrid composites. $^{(4-7)}$ Wear quantity and morphology is influenced by type of composite resins, normal force applied and presence of a third-body medium. ${ }^{(8-14)}$ Two body wear studies revealed that, microfilled composite resin showed lower material loss with smoothly worn surface, whereas microhybrid showed greater material loss with cracks in the worn surface. ${ }^{(9,10)}$ Microfilled composite wear in three body model in the presence of abrading slurry showed worn surfaces with greater failure. (11-16) Clinical evaluation of composite resin wear gives the most reliable information, despite that, laboratory wear data are still of value as numerous articles are continuously found in dental literature, reporting in vitro wear data produced with different wear testing devices..$^{(3,19,20)}$ However to assure reliable laboratory wear data, combination of at least two different wear settings is recommended to assess the wear resistance of materials. ${ }^{(21)}$

With the increasing number of nanofiller containing composite resins introduced to the market, it is still important to analyze the mechanisms resulting from two-body wear at direct contact between opposing tooth surfaces (occlusal contact area $=$ OCA: attrition), and from threebody wear (contact free area = CFA: abrasion), occurring when a food bolus is compressed between antagonist teeth and abrading particles of food slide over the restoration surface. ${ }^{(22-25)}$ Since in most cases occlusal restorations are affected by both mechanisms, it is reasonable that wear simulating devices should be designed to simulate both loading types. At this time, generally accepted in vitro wear testing methods are not approved. The ISO technical specification 14569-2:2001 "Wear by two- and/or three-body contact" gives broad recommendations. (26) Studies quantifying wear should preferably include morphological analyses of the wear patterns in order to explore the basic wear mechanisms under the different wear conditions. Apart from the production of wear patterns on specimens simulating in vivo conditions, it is equally important to apply quantitative evaluation methods, rather than semiquantitative or qualitative methods. ${ }^{(27-29)}$

Composite resin restorative materials have undergone many developments to improve the outcome of the restorative procedures specially in posterior regions of the mouth. These improvements include nanofillers technology either true nanofills or nanohybrid fillers to achieve higher filler loading with improved mechanical properties and improved surface finish. ${ }^{(1)}$ Bulk filling to save time without deleterious effects of polymerization shrinkage. ${ }^{(30)}$

Another modification is the layering technique where dentin and enamel shades are used to achieve maximum esthetics. ${ }^{(31)}$ Bioactive materials releasing fluoride, Calcium and phosphate ions are also available for application in stress bearing areas aiming at improving tooth tissue remineralization. ${ }^{(32)}$ Data on wear behavior of these newly introduced materials and antagonistic enamel wear is scarce. Hence this study was carried out to investigate the wear of some newly introduced composite resin materials intended for application in the posterior region of the mouth and to study the antagonistic enamel wear. The null hypothesis tested is no difference in wear between restorative materials and no difference in antagonistic enamel wear.

\section{MATERIALS AND METHODS}

The materials used in this study, their manufacturers, description and lot numbers are listed in table 1 
TABLE (1) Materials, Manufacturers, Description and lot numbers.

\begin{tabular}{|c|c|c|c|}
\hline Material & Manufacturer & Description & Lot No. \\
\hline Grandioso heavy flow & $\begin{array}{l}\text { VOCO, Cuxhaven, } \\
\text { Germany }\end{array}$ & $\begin{array}{l}\text { Flowable Universal nanohybrid restorative with filler } \\
\text { loading } 80 \% \text { by weight. }\end{array}$ & 1505123 \\
\hline $\begin{array}{l}\text { Activa bioactive } \\
\text { restorative. }\end{array}$ & $\begin{array}{l}\text { Pulpdent } \\
\text { corporation,MA, USA. }\end{array}$ & $\begin{array}{l}\text { is an esthetic, } \\
\text { bioactive composite that delivers the advantages of glass } \\
\text { ionomers in a strong, resilient, resin matrix. It chemically } \\
\text { bonds to teeth, releases fluoride and is more bioactive than } \\
\text { glass ionomers, and is more durable and fracture resistant } \\
\text { than composites. }\end{array}$ & 150119 \\
\hline Filtek Z250 & $\begin{array}{l}\text { 3M ESPE dental } \\
\text { products, St. Paul, USA. }\end{array}$ & $\begin{array}{l}\text { Microhybrid composite } \\
\text { specifically designed for use in both anterior and posterior } \\
\text { direct or indirect restorations. }\end{array}$ & \\
\hline Brilliant everglow & $\begin{array}{l}\text { Coltène, Whaledent AG } \\
\text { Feldwiesenstr. } 20 \\
9450 \text { Altstätten } \\
\text { Switzerland }\end{array}$ & Submicron hybrid universal composite. & G27644 \\
\hline CAPO universal & $\begin{array}{l}\text { SCHUTZ dental group, } \\
\text { Rospach, Germany. }\end{array}$ & $\begin{array}{l}\text { Ultra-fine micro hybrid } \\
\text { composite with improved abrasion characteristics. }\end{array}$ & 2013001359 \\
\hline $\begin{array}{l}\text { Herculite XRV ultra } \\
\text { enamel }\end{array}$ & $\begin{array}{l}\text { Kerr dental, Scafati, } \\
\text { Italy. }\end{array}$ & Microhybrid composite enamel shade. & 5181515 \\
\hline
\end{tabular}

\section{Composite resin material specimens preparation}

Ten cylindrical specimens $4 \mathrm{~mm}$ diameter $\mathrm{x}$ $6 \mathrm{~mm}$ length were prepared from each material. The resin composite was packed in a split Teflon mold that was covered by celluloid matrix strip on its top and bottom. A glass slide was used to extrude excess material, followed by curing the composite specimens from top and bottom for 20s each using the light curing unit (Elipar S10 free light, 3M, ESPE, USA) with an output intensity of $1200 \mathrm{~mW} /$ $\mathrm{cm}^{2}$. The light was checked for intensity every 10 specimens and in case there is drop of intensity the curing unit was put on the charger. After curing, the specimens were finished using ascending grits of silicon carbide paper $400,600,800,1000,1200$, to remove excess flashes and standardize the surface. the specimens were then kept in distilled water at $37^{\circ} \mathrm{C} \pm 1$ for $24 \mathrm{hrs}$ before wear test.

\section{Enamel specimens preparation}

30 human premolars extracted for orthodontic treatment were selected in this study. The teeth were caries and cracks free, the teeth were washed, disinfected using 1\% thymol solution for $24 \mathrm{hrs}$ after that teeth were stored in distilled water until used. The teeth were decapitated $1 \mathrm{~mm}$ below the cemento-enamel junction, the crowns were sectioned buccolingually in their center to create two equal mesial and distal halves using a diamond disc in low speed hand piece under water coolant. This yielded 60 proximal enamel surfaces that were flattened through finishing with ascending grit silicon carbide paper. The enamel specimens were kept in distilled water until used.

Thermo-mechanical aging test was conducted using the four stations multi-modal ROBOTA chewing simulator* integrated with thermo-cyclic protocol (Model ACH-09075DC-T, AD-TECH TECHNOLOGY CO., LTD., GERMANY) operated as wear simulator accompanied with thermocyclic mode, fig (1). 


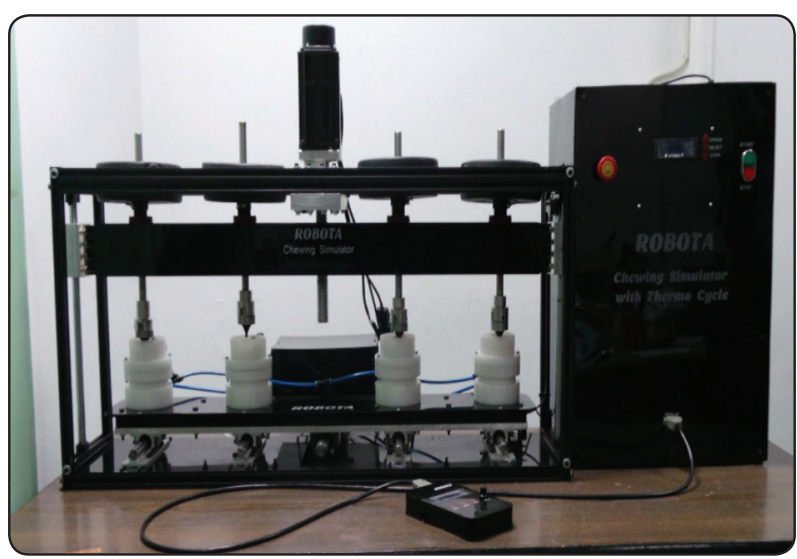

Fig. (1) Four chamber chewing simulator used for the wear test.

ROBOTA chewing simulator which has four chambers simulating the vertical and horizontal movements simultaneously in the thermodynamic condition. Each of the chambers consists of an upper stylus holder where composite specimens were tightened with a screw for use as antagonistic materials and a lower Teflon sample holder in which the enamel specimens were embedded (Fig. 2). A weight of $50 \mathrm{~N}$ of chewing force was exerted. The test was repeated 20000 times to clinically simulate the 6 month chewing condition, accompanying thermocycling.

TABLE (2) Test parameters for the chewing simulator during wear Process.

\begin{tabular}{|c|c|}
\hline \multicolumn{2}{|c|}{ Test parameters } \\
\hline $\begin{array}{l}\text { Cold/hot bath temperature: } \\
5^{\circ} \mathrm{C} / 55^{\circ} \mathrm{C}\end{array}$ & Dwell time: $60 \mathrm{~s}$ \\
\hline Vertical movement: $2 \mathrm{~mm}$ & Horizontal movement: $1 \mathrm{~mm}$ \\
\hline Rising speed: $90 \mathrm{~mm} / \mathrm{s}$ & Forward speed: $90 \mathrm{~mm} / \mathrm{s}$ \\
\hline Descending speed: $40 \mathrm{~mm} / \mathrm{s}$ & Backward speed: $40 \mathrm{~mm} / \mathrm{s}$ \\
\hline Cycle frequency $3 \mathrm{~Hz}$ & \multirow[t]{2}{*}{$\begin{array}{l}\text { Weight per sample: from } 3 \text { up } \\
\text { to } 10 \mathrm{~kg}\end{array}$} \\
\hline Torque; 2.4 N.m & \\
\hline
\end{tabular}

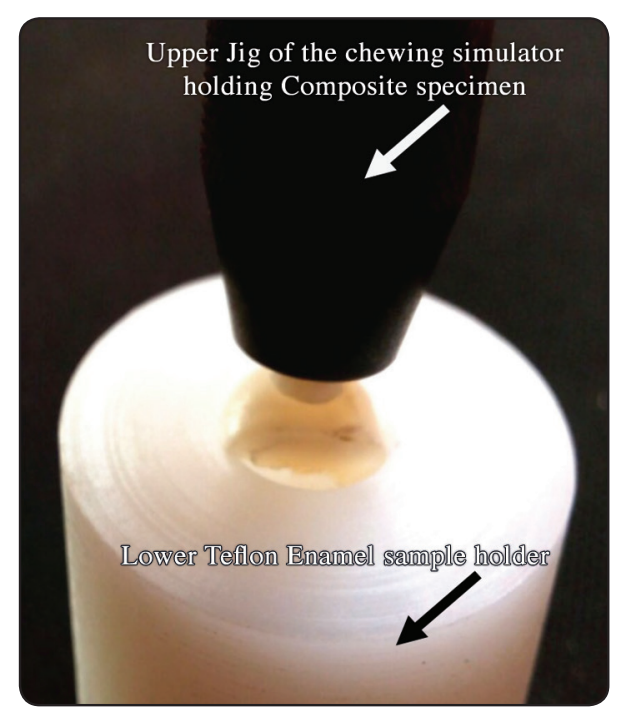

Fig (2) Test set up showing articulation of composite and enamel specimens in the wear simulator

\section{SEM Evaluation}

Two enamel specimens from each group were selected for SEM evaluation, the worn surfaces were sputter coated with gold using (S150A Sputter coater, UK ). After sputter coating the specimens were examined under SEM (Quanta 250, FEI, Amsterdam, Holland) at a magnification of 100, 1000 and 1500 to evaluate the wear scars in enamel.

\section{Statistical analysis}

The data was collected tabulated and expressed as mean \pm standard deviation. The data were subjected to test of normality using Shapiro-wilk test,g then One way ANOVA followed by Tukey's post hoc test for means comparison. The Pearson's coefficient of correlation was calculated for wear of composite and antagonistic enamel. The statistical analysis was performed using IBM, SPSS version 20.

\section{RESULTS}

The results of this study are shown in table (3) and figures( 3 and 4 )

The highest wear was that of Grandioso heavy flow $(5.8 \mathrm{mg})$ followed by brilliant everglow $(4 \mathrm{mg})$ 
and Herculite ultra enamel $(2.5 \mathrm{mg})$ respectively and there was statistically significant differences among them as well as other materials, and the least values were recorded for CAPO (1.22mg), Z250 (1.24)and Activa (1.27) that were not statistically significantly different. Regarding opposing enamel wear the highest wear value was that of enamel opposing Brilliant everglow $(7 \mathrm{mg})$ and $\mathrm{Z} 250(6.4 \mathrm{mg})$ both values were not statistically different. The values of Heculite ultra enamel (4.6) and Grandioso heavy flow $(4 \mathrm{mg}$ ) had no significant differences between them but showed significant difference with the above groups. The enamel wear opposing Activa $(1 \mathrm{mg})$ and CAPO (1.8mg) showed no statistically significant differences between them while they were significantly less than other groups.

TABLE (3) Wear results in $\mathrm{mg}$ for both composite materials and opposing enamel.

\begin{tabular}{cccc}
\hline & & $\begin{array}{c}\text { Mean wear } \\
\text { in mg }\end{array}$ & SD \\
\hline & Herculite & $2.5^{\mathrm{C}}$ & 0.6 \\
& CAPO & $1.2^{\mathrm{D}}$ & 0.2 \\
Restorative & Z250 & $1.2^{\mathrm{D}}$ & 0.4 \\
Materials & Grandioso & $5.8^{\mathrm{A}}$ & 1.3 \\
& Bioactive & $1.3^{\mathrm{D}}$ & 0.4 \\
& Brilliant & $4^{\mathrm{B}}$ & 0.9 \\
& Herculite & $4.6^{\mathrm{c}}$ & 1.2 \\
& CAPO & $1.8^{\mathrm{b}}$ & 0.5 \\
Enamel & Z250 & $6.4^{\mathrm{a}}$ & 1.2 \\
Opposing & Grandioso & $4^{\mathrm{b}}$ & 0.7 \\
Materials & Bioactive & $1^{\mathrm{c}}$ & 0.2 \\
& Brilliant & $7^{\mathrm{a}}$ & 1 \\
\hline & & & \\
& & &
\end{tabular}

Different capital superscript letters indicate significant differences between composite materials wear, whereas small superscript letters indicate significant differences for antagonistic enamel wear.

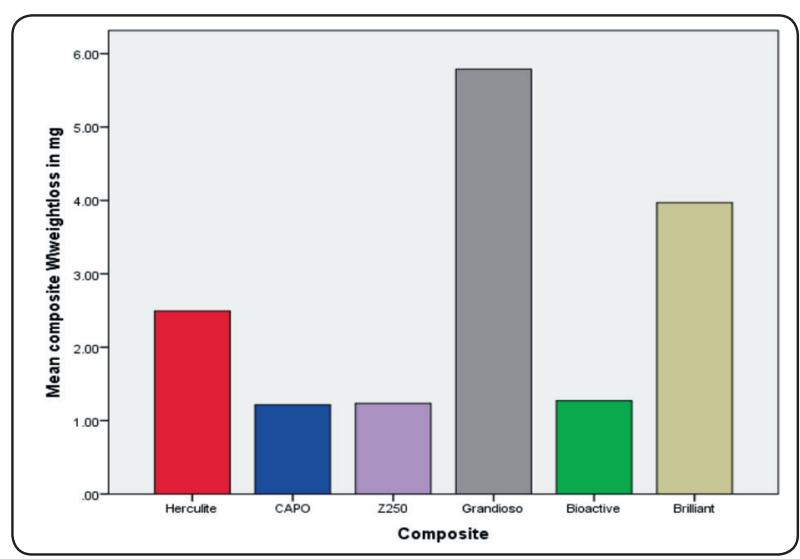

Fig (3) Bar chart showing values of composite wear against enamel in mg after 20,000 chewing cycles.

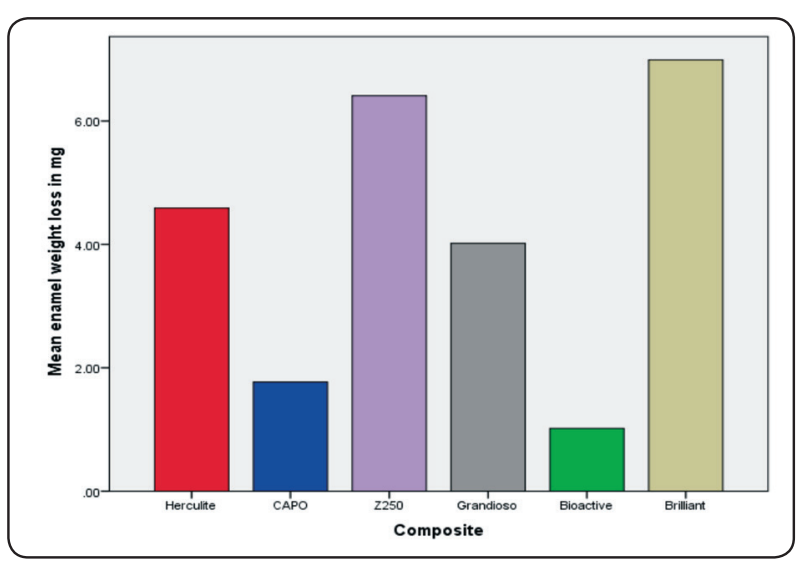

Fig (4) Bar chart showing values of human enamel wear against different materials in mg after 20,000 chewing cycles.

The correlation study showed very weak positive correlation between enamel wear and composite wear as indicated by a Pearson coefficient of only 0.28 as shown in table (4) .

TABLE (4) Correlations between enamel wear and composite wear.

\begin{tabular}{|c|c|c|c|}
\hline \multicolumn{2}{|c|}{} & $\begin{array}{c}\text { Composite } \\
\text { weight loss }\end{array}$ & $\begin{array}{c}\text { Enamel } \\
\text { weight loss }\end{array}$ \\
\hline \multirow{3}{*}{$\begin{array}{c}\text { Weight } \\
\text { loss }\end{array}$} & Pearson Correlation & 1 & $.280^{*}$ \\
\cline { 2 - 4 } & Sig. (2-tailed) & & .030 \\
\cline { 2 - 4 } & $\mathrm{N}$ & 60 & 60 \\
\hline \multirow{3}{*}{ Enamel } & Pearson Correlation & $.280^{*}$ & 1 \\
\cline { 2 - 4 } & Sig. (2-tailed) & .030 & \\
\cline { 2 - 4 } & $\mathrm{N}$ & 60 & 60 \\
\hline
\end{tabular}

*. Correlation is significant at the 0.05 level (2-tailed). 


\section{SEM Results}

The SEM examination fig (5) revealed different patterns of enamel wear, these patterns of wear by

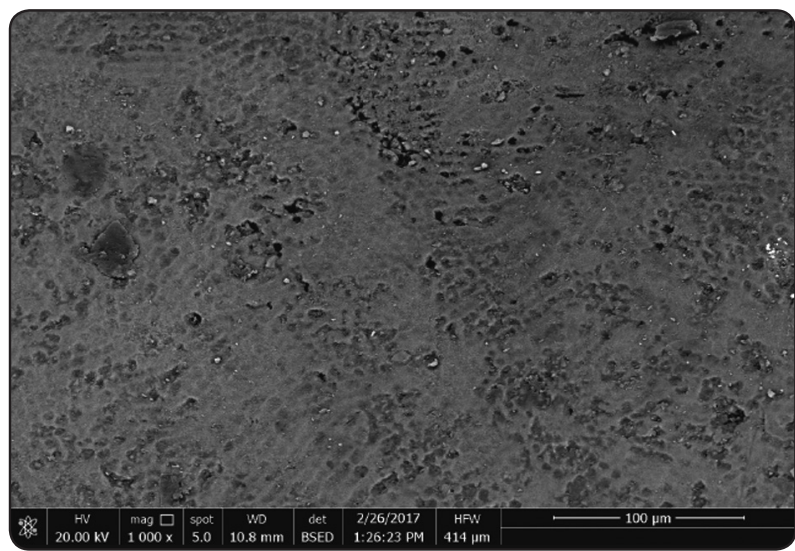

Wear scars of enamel opposing CAPO

showing mild wear cracks and scaring.

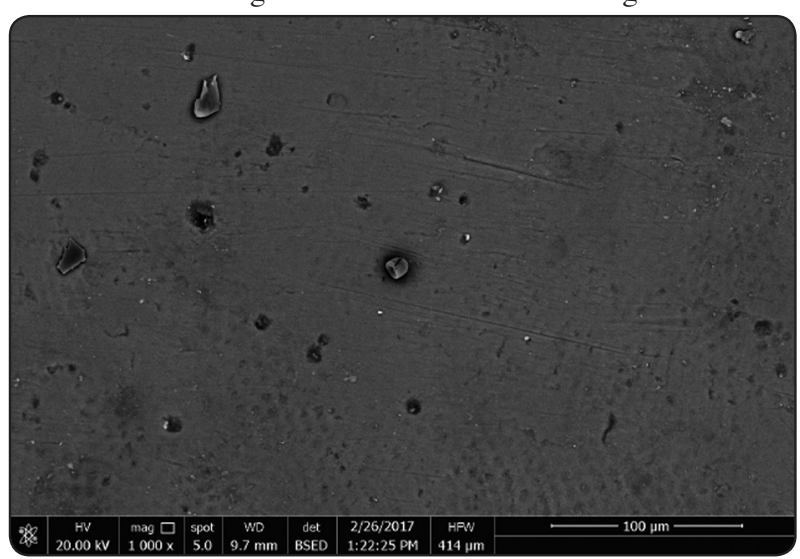

Wear scars of enamel opposing Bioactiva showing minimal scars.

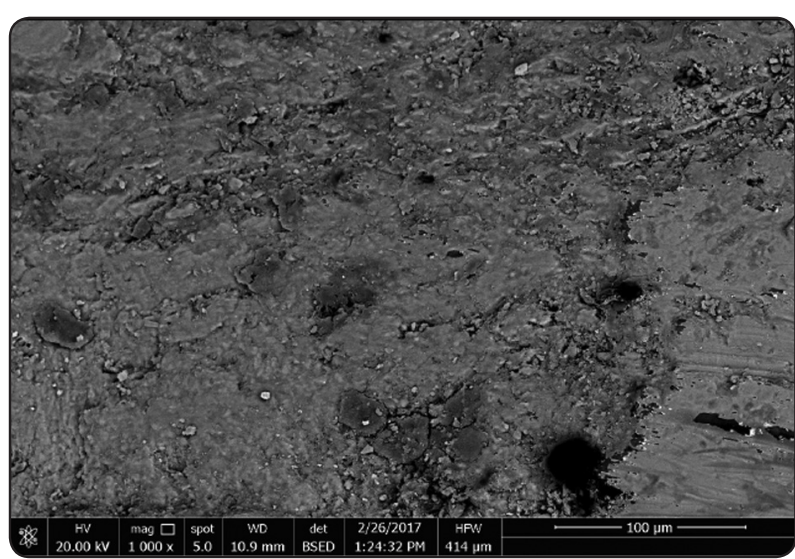

Enamel wear scars opposing Brilliant everglow showing massive enamel cracking and delamination. fatigue and brittle fracture indicated by delamination and cracking of enamel within the wear scars. The different types of composites showed different degrees of aggressiveness of wear scars.

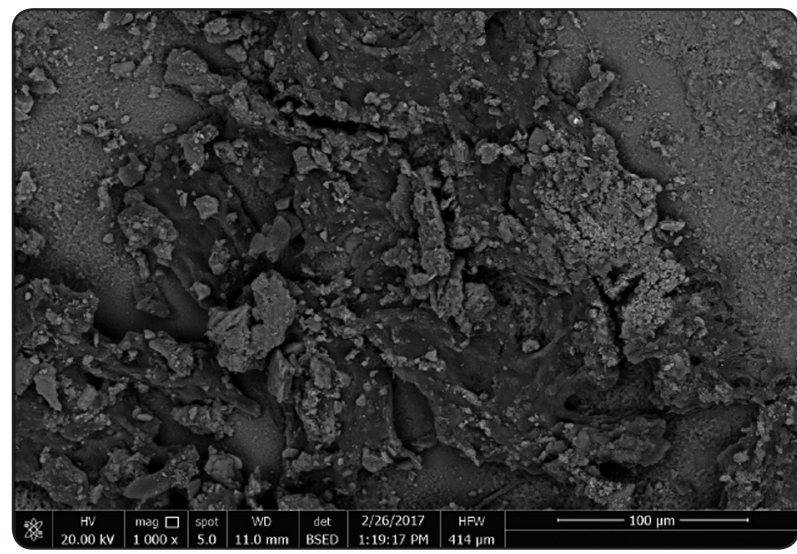

Wear scars of enamel opposing Grandioso heavy flow showing delamination of both enamel and restorative resin.

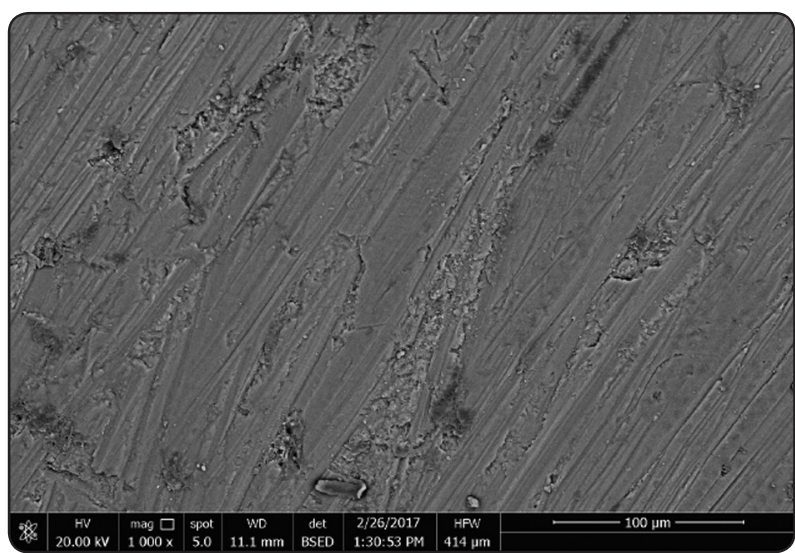

Wear scars opposing Herculite ultra showing deep scratches with enamel cracking within the scar.

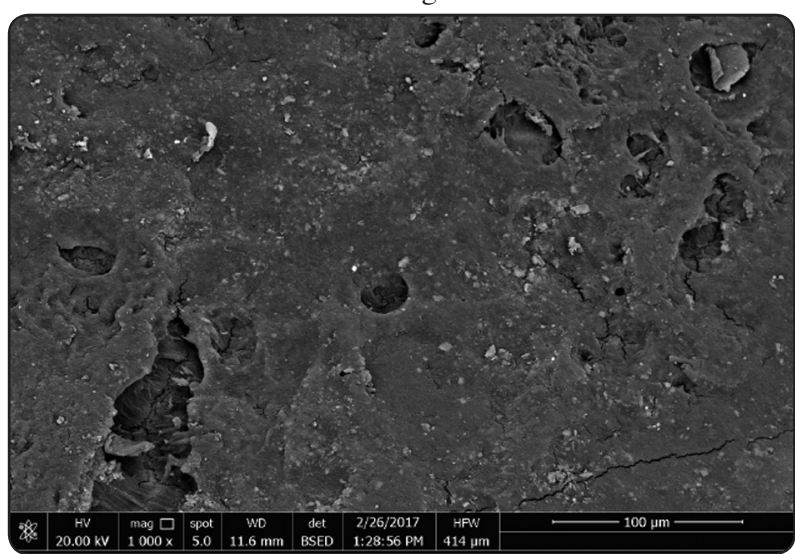

Wear scars of enamel opposing Z250 showing delamination of enamel areas with little cracks.

Fig (5) SEM photomicrographs of enamel Against different Composite resin restorative materials 


\section{DISCUSSION}

In this study six different commercially available direct composite resin restorative materials that are indicated for use opposing enamel in high stress occlusal situations were used. They were representing different categories of resin composite materials; heavily filled nanohybrid flowable composite, bioactive composite, microhybrid composite, submicron hybrid composoite, and ultrafine microhybrid composite. These materials were introduced with claims of manufacturers that they are antagonist friendly yet have high abrasion resistance. Hence this study evaluated the wear behavior of these materials and in the same time evaluated antagonistic enamel wear.

In the current study wear was evaluated using a design similar to a pin-on-disk wear-test rig, which has been very popular to simulate two-body wear between the sample and the antagonist. ${ }^{(17,33)}$ This method uses a simple relative movement between the wear pair and gives relatively quick results. ${ }^{(33)}$

When direct contact occurs in the absence of third medium, two-body abrasion takes place when the surfaces are rubbed away. ${ }^{(20)}$ In this study two body wear test setup was used as two body wear indicates the direct effect of the tested surfaces over one another with elimination of the effect of intermediate material like food. In the mouth, these conditions occur predominantly during nonmasticatory tooth movement and are particularly prevalent in 'bruxism'. (20) Attrition is a form of two-body abrasion wear, which is the result of physiological or pathological proximal and occlusal inter-dental friction. Despite extensive knowledge of the histology and mechanical properties of enamel, little is known about the wear behavior of human enamel. Reviewing the existing literature, it is found that limited detailed research has been conducted to evaluate the friction and wear behavior of human enamel. ${ }^{(33)}$

The antagonist material opposing a natural tooth affects the wear behaviour of enamel and thus, an appropriate restorative material should be carefully selected to minimize the wear of natural dentition. $^{(34)}$ The results of this study showed that the least enamel wear was that opposing Bioactiva which is a bioactive ion releasing resin modified glass ionomer, this could be due to its relatively lower surface hardness compared to other materials. The highest enamel were was recorded opposing Brilliant everglow followed by Z250 followed by Grandioso heavy flow and Herculite enamel, the lowest composite regarding enamel wear was CAPO which is claimed by the manufacturer to be enamel friendly. These results could be attributed to differences in filler particle size distribution, filler composition, filler loading and degree of crosslinking of the matrix and its physical and mechanical properties ${ }^{(16)}$. Composites that showed high opposing enamel wear had large fillers of high hardness while composites that showed minimal opposing enamel wear (CAPO) had softer fillers (Barium glass fillers).

From the results of in vitro investigations on the wear behaviour of dental enamel, it can be inferred that enamel is a unique, biocomposite that wears by brittle fracture and/or surface delamination under sliding motion. ${ }^{(35)}$ in the current study the pattern of enamel wear as indicated by SEM results showed fatigue cracks, brittle fracture and surface delaminations of enamel. Generally, the wear behaviour of composite can be associated with either material or clinical factors. Material factors relate to the characteristics, content, and distribution of filler, the degree of conversion and interfacial bond between matrix and filler. In addition, the silane coupling, the nature of matrix and surface hardness also influence the wear resistance of composite materials ${ }^{(20)}$. Condon and Ferracane, $1997^{(9)}$ investigated the effects of compositional factors including the degree of cure, filler level and silanation level on the wear resistance of three different experimental composites. The authors found that greater composite wear was correlated with lower filler levels and reduced percent of 
silane-treated fillers. In the current study the wear result showed variability in the wear results of the used composites could be attributed to the above mentioned factors. Another important key factor in composite wear is curing characteristics and degree of conversion of the matrix, Ferracane et al, $1997^{(36)}$ demonstrated a strong negative correlation between the degree of cure and the wear of the same experimental composites. It was suggested that longer curing time caused the polymer network to be more highly crosslinked, and therefore more resistant to the forces of abrasion. The different materials used in this study were ensured for proper curing as indicated by manufacturers instructions.

Within the limitations of this in vitro study it could be concluded that:

1. The different composite formulations have different wear rates.

2. Ultrafine microhybrid composite has more wear resistant, while the heavy filled flowable composites has less wear resistant than other types of composites

3. Antagonistic enamel wear must be considered as it is independent of composite wear, some materials were antagonist conserving while others were antagonist aggressive.

\section{REFERENCES}

1. Ferracane JL. Resin composite - state of the art. Dental Materials 2011;27:29-38.

2. Takahashi H, Finger WJ, Endo T, Kanehira M, Koottathape N, Komatsu M, et al. Comparative evaluation of mechanical characteristics of nanofiller containing resin composites. American Journal of Dentistry 2011;24:264-70.

3. Ferracane JL. Is the wear of dental composites still a clinical concern? Is there still a need for in vitro wear simulating devices? Dental Materials 2006;22:689-92.

4. Yesil ZD, Alapati S, Johnston W, Seghi RR. Evaluation of the wear resistance of new nanocomposite resin restorative materials. Journal of Prosthetic Dentistry 2008;99:435-43.

5. Palaniappan S, Bharadwaj D, Mattar DL, Peumans M, van Meerbeek B, Lambrechts P. Three-year randomized clinical trial to evaluate the clinical performance and wear of a nanocomposite versus a hybrid composite. Dental Materials 2009;25:1302-14.

6. Palaniappan S, Elsen L, Lijnen I, Peumans M, van Meerbeek B,Lambrechts P. Three-year randomized clinical trial to evaluate the clinical performance, quantitative and qualitative wear patterns of hybrid composite restorations. Clinical Oral Investigations 2010;14:441-58.

7. Palaniappan S, Bharadwaj D, Mattar DL, Peumans M, van Meerbeek B, Lambrechts P. Nanofilled and microhybrid composite restorations: five year clinical wear performances. Dental Materials 2011;27:692-700.

8. Lambrechts P, Braem M, Vanherle G. Buonocore memorial lecture. Evaluation of clinical performance for posterior composite resins and dentin adhesives. Operative Dentistry 1987;12:53-78.

9. Condon JR, Ferracane JL. Factors effecting dental composite wear in vitro. Journal of Biomedical Materials Research (Applied Biomaterials) 1997;38:303-13.

10. Hu X, Shortall AC, Marquis PM. Wear of three dental composites under different testing conditions. Journal of Oral Rehabilitation 2002;29:756-64.

11. $\mathrm{Hu}$ X, Marquis PM, Shortall AC. Influence of filler loading on the two-body wear of a dental composite. Journal of Oral Rehabilitation 2003;30:729-37.

12. Turssi CP, Ferracane JL, Serra MC. Abrasive wear of resin composites as related to finishing and polishing procedures. Dental Materials 2005;21:641-8.

13. Yap AU, Teoh SH, Chew CL. Effects of cyclic loading on occlusal contact area wear ;of composite restoratives. Dental Materials 2002;18:149-58.

14. Musanje L, Ferracane JL, Ferracane LL. Effects of resin formulation and nanofiller surface treatment on in vitro wear of experimental hybrid resin composite. Journal of Biomedical Materials Research Part B: Applied Biomaterials 2006;77B:120-5.

15. Yap AU. Occlusal contact area (OCA) wear of two new composite restoratives. Journal of Oral Rehabilitation 2002;29:194-200.

16. Zantner C, Kielbassa AM, Martus P, Kunzelmann KH. Sliding wear of 19 commercially available composites and compomers. Dental Materials 2004;20:277-85.

17. Hahnel S, Schultz S, Trempler C, Ach B, Handel G, Rosentritt M. Two-body wear of dental restorative materials. Journal of the Mechanical Behavior of Biomedical Materials 2011;4:237-44. 
18. Tyas MJ, Wassenaar P. Clinical evaluation of four composite resins in posterior teeth. Five-year results. Australian Dental Journal 1991;36:369-73.

19. Heintze SD. How to qualify and validate wear simulation devices and methods. Dental Materials 2006;22: 712-34.

20. Lambrechts P, Debels E, van Landuyt K, Peumans M, van Meerbeek B. How to simulate wear? Overview of existing methods. Dental Materials 2006;22:693-701.

21. Heintze SD, Barkmeier WW, Latta MA, Rousson V. Round robin test: wear of nine dental restorative materials in six different wear simulators - supplement to the round robin test of 2005. Dental Materials 2011;27:e1-9.

22. Heintze SD, Faouzi M, Rousson V, Özcan M. Correlation of wear in vivo and six laboratory wear methods. Dental Materials 2012;28:961-73.

23. Jørgensen KD, Hørsted P, Janum O, Krogh J, Schultz J. Abrasion of class I restorative resins. Scandinavian Journal of Dental Research 1979;87:140-5.

24. Lambrechts P, Vanherle G, Vuylsteke M, Davidson CL. Quantitative evaluation of the wear resistance of posterior dental restorations: a new three-dimensional measuring technique. Journal of Dentistry 1984;12:252-67.

25. Lutz F, Phillips RW, Roulet JF, Setcos JC. In vivo and in vitro wear of potential posterior composites. Journal of Dental Research 1984;63:914-20.

26. ISO. Dental materials - guidance on testing of wear. Part 2. Wear by two- and/or three-body contact. Technical Specification No 14569-2, 2001.

27. Lawson NC, Cakir D, Beck P, Litaker MS, Burgess JO. Characterization of third-body media particles and their effect on in vitro composite wear. Dental Materials 2012;28:e118-26.

28. DeLong R. Intra-oral restorative materials wear: Rethinking the current approaches: how to measure wear. Dental Materials 2006;22:702-11.

29. Gibbs CH, Mahan PE, Lundeen HC, Brehnan K, Walsh EK, Holbrook WB. Occlusal forces during chewing and swallowing as measured by sound transmission. Journal of Prosthetic Dentistry 1981;46:443-9.

30. Garcia D, Yaman P, Dennison J, Neiva G. Polymerization shrinkage and depth of cure of bulk fill flowable composite resins. Operative dentistry 2014;39(4):441-448.

31. Villaroel M, Fahl N, Maria A, De Oliveira O. Direct esthetic restorations based on translucency and opacity of composite resin. Journal of Esthetic and Restorative Dentistry 2011;23: 73-87.

32. Jeffreies $\mathrm{S}$. Bioactive and biomimetic restorative materials: A Comprehensive review. PartI. Journal of esthetic and restorative dentistry 2014;23:14-26.

33. Mueller H., Bapna, M. and Knoeppel, R. 'Human enameldental amalgam pin on disc wear,' Dental Materials 1985; 1,31-35.

34. Li H., Zhou Z. Wear behaviour of human teeth in dry and artificial saliva conditions,' Wear 2002; 249, 980-984.

35. Zheng J. Zhou, Z. R. Friction and wear behavior of human teeth under various wear conditions,' Tribol Int. 2007; 40, 278-284.

36. Ferracane J, Mitchem J, Condon J, Todd R. Wear and marginal breakdown of composites with various degrees of cure. J Dent Res. 1997; 76, 1508-1516. 